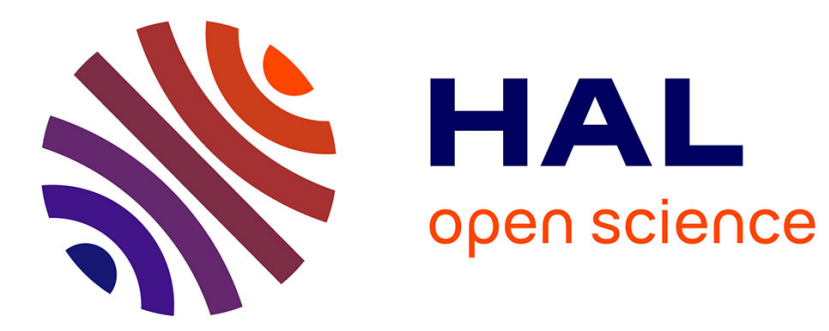

\title{
Nrf2 and AhR in metabolic reprogramming after contaminant exposure
}

Sylvie Bortoli, Elisa Boutet-Robinet, Dominique Lagadic-Gossmann, Laurence Huc

\section{- To cite this version:}

Sylvie Bortoli, Elisa Boutet-Robinet, Dominique Lagadic-Gossmann, Laurence Huc. Nrf2 and AhR in metabolic reprogramming after contaminant exposure. Current Opinion in Toxicology, 2018, 8, pp.34-41. 10.1016/j.cotox.2017.12.001 . hal-01699380

HAL Id: hal-01699380

https://hal-univ-rennes1.archives-ouvertes.fr/hal-01699380

Submitted on 7 Apr 2018

HAL is a multi-disciplinary open access archive for the deposit and dissemination of scientific research documents, whether they are published or not. The documents may come from teaching and research institutions in France or abroad, or from public or private research centers.
L'archive ouverte pluridisciplinaire HAL, est destinée au dépôt et à la diffusion de documents scientifiques de niveau recherche, publiés ou non, émanant des établissements d'enseignement et de recherche français ou étrangers, des laboratoires publics ou privés. 


\section{Accepted Manuscript}

Nrf2 and AhR in metabolic reprogramming after contaminant exposure

Sylvie Bortoli, Elisa Boutet-Robinet, Dominique Lagadic-Gossmann, Laurence Huc

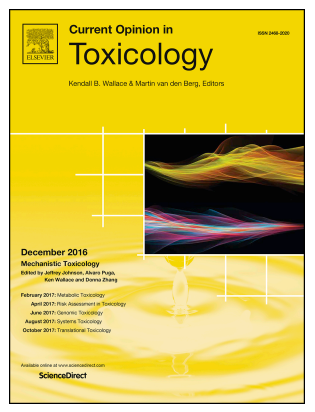

PII:

S2468-2020(17)30126-2

DOI:

10.1016/j.cotox.2017.12.001

Reference: COTOX 111

To appear in: Current Opinion in Toxicology

Received Date: 4 November 2017

Accepted Date: 8 December 2017

Please cite this article as: S. Bortoli, E. Boutet-Robinet, D. Lagadic-Gossmann, L. Huc, Nrf2 and AhR in metabolic reprogramming after contaminant exposure, Current Opinion in Toxicology (2018), doi: 10.1016/j.cotox.2017.12.001.

This is a PDF file of an unedited manuscript that has been accepted for publication. As a service to our customers we are providing this early version of the manuscript. The manuscript will undergo copyediting, typesetting, and review of the resulting proof before it is published in its final form. Please note that during the production process errors may be discovered which could affect the content, and all legal disclaimers that apply to the journal pertain. 


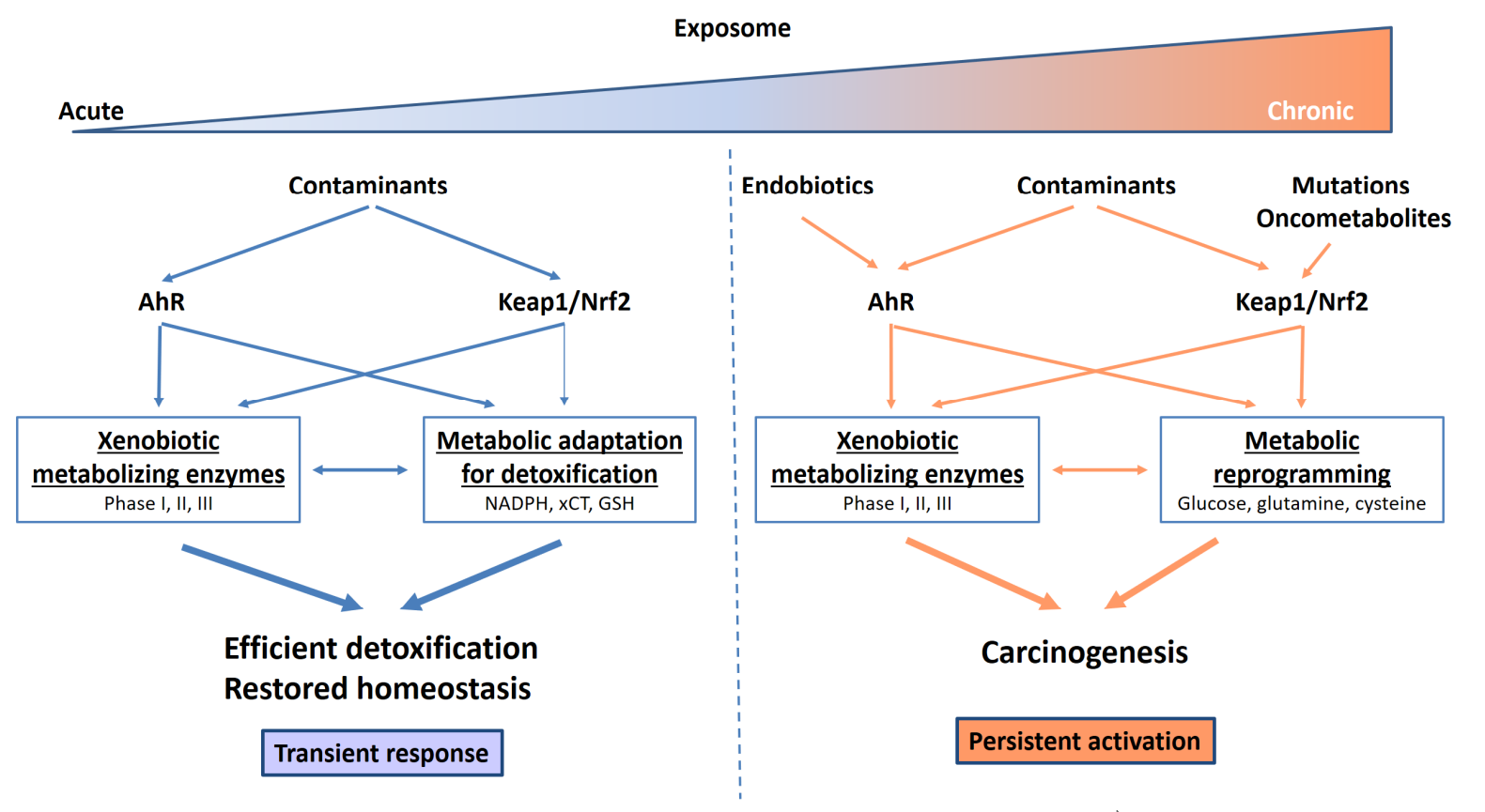




\section{Nrf2 and AhR in metabolic reprogramming after contaminant exposure}

Sylvie Bortoli ${ }^{1}$, Elisa Boutet-Robinet ${ }^{2}$, Dominique Lagadic-Gossmann ${ }^{3,4}$ \& Laurence Huc ${ }^{2}$ *

${ }^{1}$ INSERM UMR-S 1124, Université Paris Descartes, Centre Universitaire des Saints-Pères, Paris, France

${ }^{2}$ INRA UMR 1331 ToxAlim (Research Center in Food Toxicology), University of Toulouse ENVT, INP, UPS, 180 Chemin de Tournefeuille, F-31027, France

${ }^{3}$ INSERM, Institut de recherche en santé, environnement et travail (Irset - Inserm UMR 1085), F35043 Rennes, France

${ }^{4}$ Université de Rennes 1, Structure fédérative de recherche Biosit, UMS CNRS 3480/US Inserm 018, F 35043 Rennes, France

* Corresponding authors : Laurence.Huc@inra.fr, telephone: + 335820663 20, TOXALIM UMR

1331, 180 Chemin de Tournefeuille, BP 93173, 31027 Toulouse cedex 3, France.

\section{Abstract}

Beside their crucial role in xenobiotic biotransformation, AhR and Nrf2 are involved in the regulation of energetic metabolism. Nrf2, as a cytoprotective transcription factor, supply energy for detoxification and antioxidant response. AhR is ligand-activated transcriptional factor implicated in several physiological function. Following pollutant exposure, it acts as a chemosensor to eliminate harmful chemicals. Altogether, AhR and Nrf2 cooperate to contribute to protective responses upon contaminant exposure, including metabolic remodelling. This fine-tuned energetic coupling with detoxification can lead to prominent dysfunction under a chronic exposure to pollutants, and promote a long-term reprogramming that affects multiple cellular activities.

In the article, we review the involvement of Nrf2 and AhR in the metabolic adaptations that occur during the short-term cell defence upon toxicant exposure, and in the metabolic reprogramming caused by their sustained activation. We also provide several clues to highlight the potential role of the Nrf2/AhR-induced metabolic changes in environmental carcinogenesis.

\section{Highlights}

- Nrf2, as a cytoprotective transcription factor, couples detoxification and antioxidant response to energetic metabolism to neutralize toxicants efficiently.

- AhR, as a ligand-activated transcription factor, is a chemosensor that regulates xenobiotic biotransformation and can modify energetic metabolism.

- Nrf2 and AhR can orchestrate detoxification and metabolic adaptation to tackle xenobiotics assault

- Persistent activation of Nrf2 and AhR leads to sustained metabolic reprogramming related in cancer progression 


\section{1- Nrf2:}

\section{1-1 Stress sensing by Keap1-Nrf2 system.}

Nrf2 (Nuclear factor erythroid-2 related factor-2) is a bZip transcription factor involved in the antioxidant defence. Sequestered in the cytoplasm by its inhibitor Keap1, Nrf2 is constitutively synthetized and degraded by the ubiquitin-proteasome system. Following oxidative stress or xenobiotic exposure, Keap1 is oxidized on key cysteines, leading to conformational changes that liberate Nrf2. Stabilized by phosphorylation, Nrf2 enters the nucleus, and dimerized with small Maf proteins, binds DNA at specific domains called antioxidant responsive element (ARE) (5'TG/TAC/GnnnGC-3'), to activate the expression of target genes involved in antioxidant defence. Xenobiotics can also directly form adducts with Keap 1, or indirectly activate Keap1 by reactive oxygen species (ROS) or electrophiles, secondary to xenobiotic entry, bioactivation and consecutive cellular disturbance [1]. Among the referenced xenobiotics that activate Nrf2, we can note thiol reactive compounds, electrophiles generators and ROS inducers like metals and metalloids. When Nrf2 induces gene expression and is exported from the nucleus, it is trapped by Keap 1 to be degraded. The shuttle is very sensitive to oxidative stress and Nrf2 is not accumulated in the nucleus but the speed of its shuttle with Keap 1 is increased [2].

Historically, the main genes discovered to be Nrf2- targets were enzymes involved in detoxification, antioxidant response such as heme oxigenase 1 (HO1), NAD(P)H Dehydrogenase Quinone 1 (NQO1), glutathion S-transférase (GST), superoxide dismutase (SOD), catalase, aldehyde dehydrogenase, glutamate-cysteine ligase (GCL), phase II enzymes, in which we can note those involved in glutathione (GSH) conjugation and thioredoxin [3].

\section{1-2 Keap1-Nrf2 system couples detoxification to metabolic adaptation.}

Based on this process, further studies rapidly linked detoxification to energetic metabolism in relationship with cysteine, glutamine and serine metabolism for GSH and thioredoxin synthesis, pentose phosphate pathway (transketolase, glucose-6-phosphate deshydrogenase), and isocitrate deshydrogenase and malic enzyme to maintain NADPH regeneration [3].

We recently illustrated the role of NRF2-dependent coupling of detoxification process to metabolism, in colorectal cancer upon the exposure to the 4-hydroxynonenal (HNE), a neoformed contaminant of lipid oxidation. HNE triggers the activation of Nrf2 leading to the induction of the cystine transporter subunit $\mathrm{xCT}$, an antiporter that catalyses cystine influx coupled to glutamate efflux. GSTA4, allowing the conjugation of HNE to gluthatione is also induced but the dynamics of detoxification is fully coupled to cysteine metabolism. Then in preneoplastic colon cells in which Nrf2 is highly active, HNE is fully detoxified in few hours, and the metabolism returns to a basal level. The efficiency of the detoxification process is then based on the capacity of the cells to mobilize their energetic metabolism [4,5]. As we showed in normal colon cells in which the Nrf2 response is less efficient and the cysteine uptake lower, the cells accumulate damages such protein adducts and DNA lesions, and undergo into cell death [6].

\section{1-3 Nrf2 and hormetic response: low-grade stimulation as a beneficial optimization of detoxification-bioenergetic coupling}

The involvement of Nrf2 in the detoxication of a contaminant such as HNE suggests a hormetic role of Nrf2 in the case of xenobiotic exposure and chemoprevention [7]. A low-grade stimulation of Nrf2 provides a positive and protective antioxidant response, associated with a good metabolic coupling. Following toxicant exposure, cells are better prepared for defence. It is clearly the case of stem cells, which have a high potential of anti-oxidative defences. Moreover, polyphenols and others compounds naturally present in diet that stimulate Nrf2 are associated to the prevention of some 
diseases, such as cancer, cardiovascular disorders, diabetes and aging [8]. However, in the light of the involvement of Nrf2 in the detoxification process upon HNE exposure, we can hypothesise that the chronic and low dose exposure to xenobiotics could also stimulate Nrf2 system and so, maintain a protective hormesis in which the toxicant would be rapidly neutralized. This is a relevant area in the beneficial/risk balance research in the field of food toxicology and public health since humans are exposed to healthy antioxidants but also contaminants such as pesticides, neoformed contaminants, microbiota metabolites, that can stimulate Nrf2.

\section{2- AhR}

\section{2-1 Canonical role of AhR : xenobiotic metabolism}

The aryl hydrocarbon receptor (AhR) is a ligand activated transcriptional factor that is known for its role in the toxic and carcinogenic effect of various environmental pollutants, including food contaminants. AhR is involved in the adaptive regulation of xenobiotic detoxification [9]. AhR ligands include environmental pollutants such as halogenated aromatic hydrocarbons and polycyclic aromatic hydrocarbons (PAH), dietary compounds such as flavonoids and indoles, and endogenous molecules mainly derived from tryptophan metabolism such as kynurenic acid and kynurenine. Among the environmental contaminants, the prototypical ligand 2,3,7,8-tetrachlorodibenzo- $p$-dioxin (TCDD) is one of the most potent ligands of the AhR.

In the cytoplasm, AhR is bound to a multiprotein complex including Hsp90, XAP2, p23 and Src. In the canonical pathway, upon ligand exposure, the AhR complex dissociates and AhR translocates into the nucleus, where it heterodimerizes with ARNT (AhR Nuclear Translocator, also known as Hypoxic Inducible Factor $1 \beta$ (HIF1 $\beta$ )). The AhR/ARNT complex recognizes xenobiotic-responsive elements (XREs) in the promoter of target genes, inducing the expression of genes that encode phase I and II xenobiotic metabolizing enzymes, such as cytochrome P450 monooxygenases (CYP1A1, CYP1A2, and CYP1B1) and glutathione-S-transferases (GSTs), NADPH/quinone oxidoreductase (NQO1), and UDP glucuronosyl transferases $1 \mathrm{~A} 1$ and $1 \mathrm{~A} 2[9]$. This AhR triggered pathway is referred to as the canonical pathway and mediates the detoxification of AhR ligands. AhR activation mediates adverse effects upon contaminant exposure. Its activation promotes xenobiotic detoxification adaptive pathway via a process that renders hydrophobic pollutants less toxic, more hydrophilic and, therefore, facilitates their elimination. However, AhR is a mediator of the toxicity for several xenobiotics: the PAH prototype benzo[a]pyrene $(\mathrm{Ba}[\mathrm{P}])$ is rapidly metabolized by cytochromes $\mathrm{P} 450$ and aldo-keto reductases and produces diol-epoxide metabolites that are mutagenic and tumorigenic, notably through the formation of DNA-adducts [10]. Moreover, AhR-dependent detoxification leads to oxidative stress and reactive oxygen species (ROS) production resulting in oxidative damage on cellular macro-molecules such as DNA, lipids or proteins [11-13].

\section{2-2 AhR and its activity as an energetic metabolic modulator}

Upon ligand exposure, AhR activation mediates changes in cell metabolic program, as observed in several reports. The first evidence for the involvement of AhR ligands in metabolic disorders comes from the observation, at the late 1990s, of an increased prevalence of diabetes and dyslipidemia in Korean Vietnam veterans exposed to Agent Orange, a dioxin-containing herbicide massively used by United States army during the Vietnam War [14]. From these observations has emerged the hypothesis of a role of AhR activation in metabolic disorders. Numerous epidemiological studies have shown a positive association between AhR ligands such as dioxins and metabolic disorders, emphasizing the possible role of environmental contaminants in the emergence of a variety of diseases, such as hepatic steatosis, obesity, metabolic syndrome and type 2- diabetes. According to 
these observations, mechanistic studies in animal and cell models have shown that metabolic dysfunction upon contaminants exposure occurs in various cell type and tissue, such as liver, muscle, adipose tissue and skin [15-17]. Pollutant induced-metabolic reprogramming is characterized by alterations in glucose metabolism (reduced gluconeogenesis and glycogenogenolysis), lipid metabolism (stimulated lipogenesis and qualitative changes in lipid species), and a strong impairment in energy metabolism due, at least in part, to a major mitochondrial dysfunction [18].

The mechanisms underlying the role of AhR in metabolic reprogramming are multiple:

- AhR can directly act as a transcriptional factor to regulate the expression of genes involved in energy metabolism.

As referred by several transcriptomic studies in vivo in mice and in human cell lines, AhR activation leads to significant changes in the expression of genes involved in glucose, amino-acid and lipid metabolism [19-21] possibly by targeting XREs (5'-GCGTG-3') in promoters. Nault et al have recently identified putative XREs in upstream regions of 475 differentially expressed genes encoding proteins involved in glucose, amino acid, and fatty acid metabolism, in the liver of TCDD-treated mice [22]. We can note that the modulation of these metabolic pathways could be related to NADPH production and decreased oxidative stress but further studies are required for the understanding on the biotransformation-bioenergetics coupling.

- AHR can interact with several intracellular signalling pathways to regulate cell metabolism.

Cell metabolism is regulated by a large diversity of signalling pathways that interact to adapt the metabolic program to environmental constraints, and a number of these pathways are also activated by AhR, including cMyc, HIF1, PI3K/Akt and p53. Thus, AhR activation upon benzo[a]pyrene increases cMyc expression in gastric cancer cells[23] so it could participate to the well-known metabolic changes driven by cMyc in stem cells as well as in cancer cells [24]. The hypoxia-induced transcription factor HIF $1 \alpha$ strongly regulates the metabolic reprogramming during tumorigenesis, at least in part by modulating the expression of genes involved in cell metabolism [25]. In particular, it transcriptionally activates the expression of several glycolytic genes, as well as genes involved in lipid and energy metabolism. Because ARNT/HIF1 $\beta$ is a central regulator of both AhR and HIF1 $\alpha$ pathways, signalling crosstalk exists [26]. Under hypoxic condition, HIF-1 $\alpha$ can sequester ARNT leading to an inhibition of the AhR transcriptional response upon ligand exposure. Conversely, exposure to environmental contaminants may attenuate HIF-1 $\alpha$-mediated responses in hypoxic conditions. Among the signalling pathways that regulate cell metabolism, activated PI3K/Akt leads to enhanced glucose uptake and glycolysis [25]. A recent report shows that AhR/CYP1A1 signalling pathway controls human breast cancer stem cell development, maintenance, and self-renewal through $\beta$ Catenin and PTEN/Akt mechanisms [27]. We also showed that AhR activation after B[a]P exposure, leads to p53 activation involved in the mitochondrial activity of hexokinase II [28]. Altogether, these observations highlighted that the modulation of bioenergetics by AhR implies many signalling pathways. However, the role of these metabolic changes as helpers for detoxification or as a consequence of profound cellular dysfunction remains to be established.

- AhR activation disturbs cell metabolism through its capacity to modulate mitochondrial function.

Mitochondria play an important role in oxidative stress upon AhR activation by environmental contaminants, with a AhR-dependent ROS production, a mitochondrial membrane hyperpolarization, a mitochondrial matrix acidification and a decrease in mitochondrial electron transport chain activity in liver cells [29-31]. AhR was demonstrated to interact with a subunit of the ATPase synthase 
complex in absence of ligand only [32,33]. We recently showed that B[a]P-induced mitochondrial dysfunction occurs in parallel with a Warburg-like metabolic shift characterized by a reduced cell respiration and an increased lactate production. These changes were associated with alterations in the tricarboxylic acid cycle, which likely involve a reduced activity of the mitochondrial complex II [29].

\section{2-3 Xenobiotics and perturbation of the endogen functions of AhR}

Historically described for its role as xenosensor involved in detoxification process, AhR has recently been reconsidered, from studies using AhR-deficient animal models, for its implication in physiological functions such as cell proliferation and differentiation, stemness, hepatic and vascular development, peripheral and intestinal immunity and hematopoiesis. Hence, xenobiotic-mediated toxicity is partly due to sustained and inappropriate AhR activation, leading to the deregulation of physiologic functions. Thus, immune function disturbances are observed in AhR- null mice (Fernandez-Salguero et al., 1995), suggesting that AhR participates in immune cell regulation. Several studies have shown that AhR is expressed in hematopoietic stem cells, thymocytes, dendritic cells and $T$ cells, and participates to both innate and adaptive immune responses through various mechanisms, including repression of acute-phase response genes, differentiation of regulatory $T$ cell lymphocytes and regulation of B cell differentiation[34,35]. Energy metabolism is critical for Tlymphocyte fate and effector functions, thus the ability of AhR activation to trigger a metabolic shift might be involved in AhR-induced regulation of immune function. This hypothesis is supported by a recent report showing that mycophenolic acid, an AhR ligand used as immune-suppressor, decreases proliferation and promotes apoptosis of T cells, in parallel with a profound metabolic reprogramming characterized by a decrease of glycolytic and glutaminolytic fluxes [36]. T cells activation also requires specialized metabolic programs that involve glycolysis, fatty acid metabolism and mitochondrial function, and modulations of metabolic profile can affect the development of Thelper cell lineages [37]. Thus the perturbation of metabolic reprogramming by AhR ligands might alter $T$ cell activation and differentiation, and in fine, compromise the immune response.

Multiple endogenous AhR agonists have been highlighted, including AhR ligands derived from microbiota- or host-cell-mediated tryptophan metabolism, which have an important role in mammalian gut immune homeostasis [38]. In particular, the tryptophan derived L-kynurenine activates AhR in lymphoid tissues [39] and promotes Treg cell development[40]. Thus AhR activation by xenobiotics may lead to excessive CYP1A1-mediated metabolic clearance of endogenous AhR ligands that might affect the intestinal immune system and cause a dramatic disruption of endobiotic homeostasis [41]. The crosstalk between physiological function of AhR and its role in detoxification process is a promising field of investigation, in particular in the context of non- biotransformed AhR ligands such as dioxins, whose exposition leads to a chronical and sustained activation of AhR.

\section{3- Nrf2 and AhR: friends or foes for energetic metabolism?}

The cooperation of Nrf2 and AhR is multiple. Firstly, the ROS production consecutive to AhRmediated biotransformation can stimulate Nrf2. Secondly, several target genes exhibit ARE and XRE in their promoter and so, their expression can be increased by Nrf2 and AhR, like NQO1. Finally, AhR and Nrf2 mutually stimulate their expression by a direct transcriptional activity.

Upon xenobiotic exposure, Nrf2 and AhR mediate cytoprotection by inducing the effective enzymes for detoxification and modulate metabolic pathways in order to supply energy to assume a protective activity. These processes are supposed to be transient and allow the survival of the 
attacked cells. When the exposure is persistent or repeated, or when the activation of Nrf2 or AhR is chronic, the metabolic dysfunction can occur, as it is the case in cancer.

\section{3-1 Sustained metabolic reprogramming mediated by Nrf2 and/or AhR in cancer: pro-tumoral activity}

Metabolic reprogramming is a hallmark of cancer cells that shift from an oxidative to a glycolytic metabolism during tumorigenesis (Warburg effect), allowing cancer cells to expand their metabolic repertoire in order to better meet their needs for proliferation, growth and survival [42]. Therefore, environmental events that promote metabolic disruption that confer advantage to or promote expansion of transformed cells initiation could be involved in the cancer promotion and/or progression.

Nrf2 and Keap1 were identified to be mutated and constitutively active in tumours [43]. Then, a higher activation of Nrf2 confers a better defence for cancer cells regarding oxidative stress, associated with hypoxia, by-products of anabolism and mitochondrial dysfunction. Many works dealt with Nrf2 metabolic reprogramming in cancer. Then, Nrf2 activation redirects glucose and glutamine through anabolic processes and promotes pentose phosphate pathway. It favours NADPH regeneration and nucleotide synthesis for proliferation [44]. Moreover, to provide enough GSH, Nrf2 enhances the dependence for exogenous glutamine via XCT activity, and it limits the flux of glutamate in the TCA cycle [45]. These profound changes underline the tiny balance between antioxidant defence and the metabolic pathways by which the tumor will grow. However, Nrf2 also negatively regulates the expression of enzymes involved in lipid biosynthesis but the mechanisms are still unknown [3].

The uncontrolled activation of $\mathrm{Nrf2}$ is also a dramatic process against anti-tumour treatments (chemotherapies, radiotherapies)[46]. Moreover, the oncometabolite namely fumarate, associated to Warburg's effect, can constitutively activate Nrf2 and so contribute to the tumorigenic vicious circle of metabolic reprogramming [47]. It is the double-sword effect of Nrf2, as a promoter of carcinogenesis when activated at later stages.

AhR is also a crucial modulator of cell metabolism that can trigger, as an adaptive response to oxidative stress, a metabolic reprogramming that might contribute to augment cell defence. In line with this hypothesis, we recently provide evidences that the AhR ligand $B[a] P$ induces a cell survival associated with an epithelial-to-mesenchymal transition and increased cell migration capacities in rat liver F258 epithelial cell. These cellular effects are associated with a metabolic reprogramming characterized by a reduced cell respiration, an increased lactate production, and an increase of pentose phosphate pathway activity that is known to produce anti-oxidant species such as NAPDH. $\mathrm{B}[\mathrm{a}] \mathrm{P}$ exposure also leads to mitochondrial dysfunction with a mitochondrial hyperpolarization and alterations in the tricarboxylic acid cycle associated with a Warburg-like metabolic reprogramming $[29,31]$. When considering that AhR also mediates $B$ [a]P bioactivation and the production of reactive metabolites and ROS, the cellular survival sustained by the metabolic reprogramming would increase genome instability and mutagenicity. Apoptosis should be seen as a process to evade carcinogenesis triggered by $\mathrm{B}[\mathrm{a}] \mathrm{P}$.

Recently in hepatocarcinoma, Zacharewski's team showed that AhR activation promotes pyruvate kinase switching to pyruvate kinase $M 2$ isoform, leading to a reduced glycolytic flux and the accumulation of upstream intermediates. The glycolytic metabolites were redirected to the pentose phosphate pathway and serine/folate biosynthesis to satisfy increasing NADPH demand, and finally maintain redox balance [48]. 
Thus, Nrf2 and AhR activation upon contaminant exposure leads to the implementation of a balance survival/death regulated by metabolic reprogramming as a way to select and expand clones able to evade growth arrest and apoptosis. Hence, the modulation of cell metabolism by environmental pollutants could be considered as a key factor in their carcinogenic potential.

\section{4- Perspectives in carcinogenesis upon xenobiotic exposure}

\section{4-1 Autophagy: convergence for repair and energy control}

Autophagy is a cellular process associated with repair of damaged organites and degradation of misfolded and aggregated proteins. The formation of autophagosomes and their fusion with lysosomes is an effective energetic recycling through catabolism. Nrf2 is connected to autophagy via the regulation loop between p62 as a target gene of Nrf2 and as a regulator of Keap 1 degradation by selective autophagy $[49,50]$. Then the activation of Nrf2 associated with autophagy could constitute an efficient way to protect cells against xenobiotics.

\section{4-2From hormesis to aging and tumorigenesis}

As the stimulation of Nrf2 at low grade can mediate a good cellular prevention, we can wonder whether the chronic exposure to toxicants at low dose could mediate hormesis as natural compounds do, or whether it accelerates aging and lately carcinogenesis.

Moreover, as for constitutive activation of Nrf2 when mutated in cancer, does a persistent activation of Nrf2 by toxicants promote tumorigenesis and metabolic reprogramming? These points should be considered as key topics in food toxicology.

\section{4-3 Metastasis: migration and EMT triggered by AhR}

Increasing evidences demonstrate a tight correlation between metabolic reprogramming and EMT implementation, in order to allow cancer cells to bypass the nutrients and oxygen supply limitation caused by the rapid primary cancer growth, and to sustain energy and nutrients demand to colonize secondary sites [51]. Several recent studies have highlighted that AhR activation upon environmental contaminants leads to morphological changes associated loss of cell-cell contact that is known to be a critical regulator of proliferation, differentiation and cell motility. AhR participates directly as a transcription factor in the AhR-dependent increase of Slug expression, which leads to an AhRdependent downregulation of the mesenchymal marker vimentin, in the context of the EMT implementation [52]. We have also identified that upon TCDD exposure, several targets of the AhR pathway play a crucial role in cell proliferation (Son of Sevenless) and cell migration (Human Enhancer of Filamentation), through an activation of Ras and Jun pathway, respectively[53,54].

AhR activation also mediates the cellular remodelling of cellular focal adhesion and cell migration via the Src signaling pathway [55]. Altogether, these observations support the hypothesis that the role of AhR in cell migration and invasiveness capacities might be linked to its ability to modulate cell metabolic program.

The hierarchical relationship between AhR, metabolic reprogramming, and EMT/migration upon AhR remain to decipher. AhR ligands should be challenged in order to determine if the AhR-induced metabolic shift is required to achieve EMT and migration, or whether it is the AhR-induced EMT that triggers metabolic changes [18]. 


\section{Acknowledgements}

This review is dedicated to those who experience science with passion and determination, in particular our colleagues and friends we miss, Pr Stefan Grimm and Dr Maxime Clusel.

LH would like to thank Maryse Baradat, Sabine Dalleau and Reggie Surya as travelling companions in the experimental exploration of detoxification and energetic pathways.

We thank Dr Chantal Benelli for exciting discussions and unconditional support.

The authors are supported by grants: ITMO Cancer AVIESAN within the framework of the Cancer Plan for METAhCOL ( $\left.n^{\circ} 17 C E 041\right)$ (SB, EBR, DLG and LH,) for NeoMeaTox ( $n^{\circ}$ ENV201213)(LH), for ONCOMETABOTOX ( $n^{\circ}$ P027395) and ANR ALIA SecuriViande (ANR-10-ALIA-14) (LHL).

\section{Bibliography}

[1] T. Suzuki, M. Yamamoto, Stress-sensing mechanisms and the physiological roles of the Keap1Nrf2 system during cellular stress, J Biol Chem. 292 (2017) 16817-16824. doi:10.1074/jbc.R117.800169.

[2] M. Xue, H. Momiji, N. Rabbani, G. Barker, T. Bretschneider, A. Shmygol, D.A. Rand, P.J. Thornalley, Frequency Modulated Translocational Oscillations of Nrf2 Mediate the Antioxidant Response Element Cytoprotective Transcriptional Response, Antioxid. Redox Signal. 23 (2014) 613-629. doi:10.1089/ars.2014.5962.

[3] J.D. Hayes, A.T. Dinkova-Kostova, The Nrf2 regulatory network provides an interface between redox and intermediary metabolism, Trends Biochem. Sci. 39 (2014) 199-218. doi:10.1016/j.tibs.2014.02.002.

[4] M. Baradat, I. Jouanin, S. Dalleau, S. Tache, M. Gieules, L. Debrauwer, C. Canlet, L. Huc, J. Dupuy, F.H. Pierre, F. Gueraud, 4-Hydroxy-2(E)-nonenal metabolism differs in Apc(+/+) cells and in $\mathrm{Apc}(\mathrm{Min} /+)$ cells: it may explain colon cancer promotion by heme iron, Chem Res Toxicol. 24 (2011) 1984-93. doi:10.1021/tx2003036.

[5] S. Dalleau, M. Baradat, F. Gueraud, L. Huc, Cell death and disease related to oxidative stress: 4 hydroxynonenal (HNE) in the balance, Cell Death Differ.

[6] R. Surya, C. Héliès-Toussaint, O.C. Martin, T. Gauthier, F. Guéraud, S. Taché, N. Naud, I. Jouanin, C. Chantelauze, D. Durand, C. Joly, E. Pujos-Guillot, F.H. Pierre, L. Huc, Red meat and colorectal cancer: Nrf2-dependent antioxidant response contributes to the resistance of preneoplastic colon cells to fecal water of hemoglobin- and beef-fed rats, Carcinogenesis. 37 (2016) 635-645. doi:10.1093/carcin/bgw035.

[7] V. Calabrese, C. Cornelius, A.T. Dinkova-Kostova, E.J. Calabrese, M.P. Mattson, Cellular stress responses, the hormesis paradigm, and vitagenes: novel targets for therapeutic intervention in neurodegenerative disorders, Antioxid. Redox Signal. 13 (2010) 1763-1811. doi:10.1089/ars.2009.3074.

[8] H.K. Bayele, E.S. Debnam, K.S. Srai, Nrf2 transcriptional derepression from Keap1 by dietary polyphenols, Biochem. Biophys. Res. Commun. 469 (2016) 521-528. doi:10.1016/j.bbrc.2015.11.103.

[9] C. Köhle, K.W. Bock, Coordinate regulation of Phase I and II xenobiotic metabolisms by the Ah receptor and Nrf2, Biochem. Pharmacol. 73 (2007) 1853-1862. doi:10.1016/j.bcp.2007.01.009.

[10] H. Dong, R.R. Bonala, N. Suzuki, F. Johnson, A.P. Grollman, S. Shibutani, Mutagenic potential of benzo[a]pyrene-derived DNA adducts positioned in codon 273 of the human P53 gene, Biochemistry (Mosc.). 43 (2004) 15922-15928. doi:10.1021/bi0482194.

[11] N.E. Landvik, V.M. Arlt, E. Nagy, A. Solhaug, X. Tekpli, H.H. Schmeiser, M. Refsnes, D.H. Phillips, D. Lagadic-Gossmann, J.A. Holme, 3-Nitrobenzanthrone and 3-aminobenzanthrone induce DNA 
damage and cell signalling in Hepa1c1c7 cells, Mutat. Res. 684 (2010) 11-23. doi:10.1016/j.mrfmmm.2009.11.004.

[12] T.D. Phillips, M. Richardson, Y.-S.L. Cheng, L. He, T.J. McDonald, L.H. Cizmas, S.H. Safe, K.C. Donnelly, F. Wang, B. Moorthy, G.-D. Zhou, Mechanistic relationships between hepatic genotoxicity and carcinogenicity in male B6C3F1 mice treated with polycyclic aromatic hydrocarbon mixtures, Arch. Toxicol. 89 (2015) 967-977. doi:10.1007/s00204-014-1285-8.

[13] P. Rossner, S. Strapacova, J. Stolcpartova, J. Schmuczerova, A. Milcova, J. Neca, V. Vlkova, T. Brzicova, M. Machala, J. Topinka, Toxic Effects of the Major Components of Diesel Exhaust in Human Alveolar Basal Epithelial Cells (A549), Int. J. Mol. Sci. 17 (2016). doi:10.3390/ijms17091393.

[14] S.-W. Yi, J.-S. Hong, H. Ohrr, J.-J. Yi, Agent Orange exposure and disease prevalence in Korean Vietnam veterans: the Korean veterans health study, Environ. Res. 133 (2014) 56-65. doi:10.1016/j.envres.2014.04.027.

[15] D.N. Das, P.P. Naik, S. Mukhopadhyay, P.K. Panda, N. Sinha, B.R. Meher, S.K. Bhutia, Elimination of dysfunctional mitochondria through mitophagy suppresses benzo[a]pyrene-induced apoptosis, Free Radic. Biol. Med. 112 (2017) 452-463. doi:10.1016/j.freeradbiomed.2017.08.020.

[16] S. Lin, Z. Yang, H. Liu, Z. Cai, Metabolomic analysis of liver and skeletal muscle tissues in C57BL/6J and DBA/2J mice exposed to 2,3,7,8-tetrachlorodibenzo-p-dioxin, Mol. Biosyst. 7 (2011) 1956-1965. doi:10.1039/c1mb05057e.

[17] R. Nault, K.A. Fader, T.A. Lydic, T.R. Zacharewski, Lipidomic Evaluation of Aryl Hydrocarbon Receptor-Mediated Hepatic Steatosis in Male and Female Mice Elicited by 2,3,7,8Tetrachlorodibenzo-p-dioxin, Chem. Res. Toxicol. 30 (2017) 1060-1075. doi:10.1021/acs.chemrestox.6b00430.

[18] R. Brooks Robey, Judith Weisz, Nancy Kuemmerle, Anna C. Salzberg, Arthur Berg, Dustin G. Brown, Laura Kubik, Roberta Palorini, Fahd Al-Mulla, Rabeah Al-Temaimi, Annamaria Colacci, Chiara Mondello, Jayadev Raju, Jordan Woodrick, A. Ivana Scovassi, Neetu Singh, Monica Vaccari, Rabindra Roy, Stefano Forte, Lorenzo Memeo, Hosni K. Salem, Amedeo Amedei, Roslida A. Hamid, Graeme P. Williams, Leroy Lowe, Joel Meyer, Francis L. Martin, William H. Bisson, Ferdinando Chiaradonna, Elizabeth P. Ryan, Metabolic reprogramming and dysregulated metabolism: cause, consequence and/or enabler of environmental carcinogenesis?, Metab. Reprogramming Dysregulated Metab. Cause Consequence Enabler Environ. Carcinog. 36 (2015). doi:10.1093/carcin/bgv037.

[19] A. Ambolet-Camoit, C. Ottolenghi, A. Leblanc, M.J. Kim, F. Letourneur, S. Jacques, N. Cagnard, C. Guguen-Guillouzo, R. Barouki, M. Aggerbeck, Two persistent organic pollutants which act through different xenosensors (alpha-endosulfan and 2,3,7,8 tetrachlorodibenzo-p-dioxin) interact in a mixture and downregulate multiple genes involved in human hepatocyte lipid and glucose metabolism, Biochimie. 116 (2015) 79-91. doi:10.1016/j.biochi.2015.07.003.

[20] E. Dere, R. Lo, T. Celius, J. Matthews, T.R. Zacharewski, Integration of genome-wide computation DRE search, AhR ChIP-chip and gene expression analyses of TCDD-elicited responses in the mouse liver, BMC Genomics. 12 (2011) 365. doi:10.1186/1471-2164-12-365.

[21] S. Sato, H. Shirakawa, S. Tomita, Y. Ohsaki, K. Haketa, O. Tooi, N. Santo, M. Tohkin, Y. Furukawa, F.J. Gonzalez, M. Komai, Low-dose dioxins alter gene expression related to cholesterol biosynthesis, lipogenesis, and glucose metabolism through the aryl hydrocarbon receptormediated pathway in mouse liver, Toxicol. Appl. Pharmacol. 229 (2008) 10-19. doi:10.1016/j.taap.2007.12.029.

[22] R. Nault, K.A. Fader, D.A. Ammendolia, P. Dornbos, D. Potter, B. Sharratt, K. Kumagai, J.R. Harkema, S.Y. Lunt, J. Matthews, T. Zacharewski, Dose-Dependent Metabolic Reprogramming and Differential Gene Expression in TCDD-Elicited Hepatic Fibrosis, Toxicol. Sci. Off. J. Soc. Toxicol. 154 (2016) 253-266. doi:10.1093/toxsci/kfw163.

[23] Y. Wei, L. Zhao, W. He, J. Yang, C. Geng, Y. Chen, T. Liu, H. Chen, Y. Li, Benzo[a]pyrene promotes gastric cancer cell proliferation and metastasis likely through the Aryl hydrocarbon receptor 
and ERK-dependent induction of MMP9 and c-myc, Int. J. Oncol. 49 (2016) 2055-2063. doi:10.3892/ijo.2016.3674.

[24] R. Ho, C. Chronis, K. Plath, Mechanistic insights into reprogramming to induced pluripotency, J. Cell. Physiol. 226 (2011) 868-878. doi:10.1002/jcp.22450.

[25] P.S. Ward, C.B. Thompson, Metabolic reprogramming: a cancer hallmark even warburg did not anticipate, Cancer Cell. 21 (2012) 297-308. doi:10.1016/j.ccr.2012.02.014.

[26] S.U. Vorrink, F.E. Domann, Regulatory crosstalk and interference between the xenobiotic and hypoxia sensing pathways at the AhR-ARNT-HIF1 $\alpha$ signaling node, Chem. Biol. Interact. 218 (2014) 82-88. doi:10.1016/j.cbi.2014.05.001.

[27] A. Al-Dhfyan, A. Alhoshani, H.M. Korashy, Aryl hydrocarbon receptor/cytochrome P450 1A1 pathway mediates breast cancer stem cells expansion through PTEN inhibition and $\beta$-Catenin and Akt activation, Mol. Cancer. 16 (2017) 14. doi:10.1186/s12943-016-0570-y.

[28] L. Huc, X. Tekpli, J.A. Holme, M. Rissel, A. Solhaug, C. Gardyn, G. Le Moigne, M. Gorria, M.T. Dimanche-Boitrel, D. Lagadic-Gossmann, c-Jun NH2-terminal kinase-related $\mathrm{Na}+/ \mathrm{H}+$ exchanger isoform 1 activation controls hexokinase II expression in benzo(a)pyrene-induced apoptosis, Cancer Res. 67 (2007) 1696-705.

[29] K. Hardonnière, E. Saunier, A. Lemarié, M. Fernier, I. Gallais, C. Héliès-Toussaint, B. Mograbi, S. Antonio, P. Bénit, P. Rustin, M. Janin, F. Habarou, C. Ottolenghi, M.-T. Lavault, C. Benelli, O. Sergent, L. Huc, S. Bortoli, D. Lagadic-Gossmann, The environmental carcinogen benzo[a]pyrene induces a Warburg-like metabolic reprogramming dependent on NHE1 and associated with cell survival, Sci. Rep. 6 (2016) 30776. doi:10.1038/srep30776.

[30] K. Hardonnière, L. Huc, O. Sergent, J.A. Holme, D. Lagadic-Gossmann, Environmental carcinogenesis and $\mathrm{pH}$ homeostasis: Not only a matter of dysregulated metabolism, Semin. Cancer Biol. 43 (2017) 49-65. doi:10.1016/j.semcancer.2017.01.001.

[31] L. Huc, L. Sparfel, M. Rissel, M.-T. Dimanche-Boitrel, A. Guillouzo, O. Fardel, D. LagadicGossmann, Identification of $\mathrm{Na}+\mathrm{H}+$ exchange as a new target for toxic polycyclic aromatic hydrocarbons, FASEB J. Off. Publ. Fed. Am. Soc. Exp. Biol. 18 (2004) 344-346. doi:10.1096/fj.030316fje.

[32] K. Hardonnière, M. Fernier, I. Gallais, B. Mograbi, N. Podechard, E. Le Ferrec, N. Grova, B. Appenzeller, A. Burel, M. Chevanne, O. Sergent, L. Huc, S. Bortoli, D. Lagadic-Gossmann, Role for the ATPase inhibitory factor 1 in the environmental carcinogen-induced Warburg phenotype, Sci. Rep. 7 (2017) 195. doi:10.1038/s41598-017-00269-7.

[33] D.M. Tappenden, S.G. Lynn, R.B. Crawford, K. Lee, A. Vengellur, N.E. Kaminski, R.S. Thomas, J.J. LaPres, The aryl hydrocarbon receptor interacts with ATP5 $\alpha 1$, a subunit of the ATP synthase complex, and modulates mitochondrial function, Toxicol. Appl. Pharmacol. 254 (2011) 299-310. doi:10.1016/j.taap.2011.05.004.

[34] A. Bessede, M. Gargaro, M.T. Pallotta, D. Matino, G. Servillo, C. Brunacci, S. Bicciato, E.M.C. Mazza, A. Macchiarulo, C. Vacca, R. Iannitti, L. Tissi, C. Volpi, M.L. Belladonna, C. Orabona, R. Bianchi, T.V. Lanz, M. Platten, M.A. Della Fazia, D. Piobbico, T. Zelante, H. Funakoshi, T. Nakamura, D. Gilot, M.S. Denison, G.J. Guillemin, J.B. DuHadaway, G.C. Prendergast, R. Metz, M. Geffard, L. Boon, M. Pirro, A. Iorio, B. Veyret, L. Romani, U. Grohmann, F. Fallarino, P. Puccetti, Aryl hydrocarbon receptor control of a disease tolerance defence pathway, Nature. 511 (2014) 184-190. doi:10.1038/nature13323.

[35] F.J. Quintana, D.H. Sherr, Aryl hydrocarbon receptor control of adaptive immunity, Pharmacol. Rev. 65 (2013) 1148-1161. doi:10.1124/pr.113.007823.

[36] A.A. Fernández-Ramos, C. Marchetti-Laurent, V. Poindessous, S. Antonio, C. Petitgas, I. Ceballos-Picot, P. Laurent-Puig, S. Bortoli, M.-A. Loriot, N. Pallet, A comprehensive characterization of the impact of mycophenolic acid on the metabolism of Jurkat T cells, Sci. Rep. 7 (2017) 10550. doi:10.1038/s41598-017-10338-6.

[37] L. Almeida, M. Lochner, L. Berod, T. Sparwasser, Metabolic pathways in T cell activation and lineage differentiation, Semin. Immunol. 28 (2016) 514-524. doi:10.1016/j.smim.2016.10.009. 
[38] A. Korecka, A. Dona, S. Lahiri, A. Tett, M. Al-Asmakh, V. Braniste, R. D'Arienzo, A. Abbaspour, N. Reichardt, Y. Fujii-Kuriyama, J. Rafter, A. Narbad, E. Holmes, J. Nicholson, V. Arulampalam, S. Pettersson, Bidirectional communication between the Aryl hydrocarbon Receptor (AhR) and the microbiome tunes host metabolism, Npj Biofilms Microbiomes. 2 (2016) 16014. doi:10.1038/npjbiofilms.2016.14.

[39] C.A. Opitz, U.M. Litzenburger, F. Sahm, M. Ott, I. Tritschler, S. Trump, T. Schumacher, L. Jestaedt, D. Schrenk, M. Weller, M. Jugold, G.J. Guillemin, C.L. Miller, C. Lutz, B. Radlwimmer, I. Lehmann, A. von Deimling, W. Wick, M. Platten, An endogenous tumour-promoting ligand of the human aryl hydrocarbon receptor, Nature. 478 (2011) 197-203. doi:10.1038/nature10491.

[40] J.D. Mezrich, J.H. Fechner, X. Zhang, B.P. Johnson, W.J. Burlingham, C.A. Bradfield, An interaction between kynurenine and the aryl hydrocarbon receptor can generate regulatory $T$ cells, J. Immunol. Baltim. Md 1950. 185 (2010) 3190-3198. doi:10.4049/jimmunol.0903670.

[41] C. Schiering, E. Wincent, A. Metidji, A. Iseppon, Y. Li, A.J. Potocnik, S. Omenetti, C.J. Henderson, R.C. Wolf, D.W. Nebert, B. Stockinger, Feedback control of AHR signalling regulates intestinal immunity, Nature. 542 (2017) 242-245. doi:10.1038/nature21080.

[42] M.G. Vander Heiden, L.C. Cantley, C.B. Thompson, Understanding the Warburg effect: the metabolic requirements of cell proliferation, Science. 324 (2009) 1029-1033. doi:10.1126/science.1160809.

[43] L.M. Solis, C. Behrens, W. Dong, M. Suraokar, N.C. Ozburn, C.A. Moran, A.H. Corvalan, S. Biswal, S.G. Swisher, N.B. Bekele, J.D. Minna, D.J. Stewart, I.I. Wistuba, Nrf2 and Keap1 Abnormalities in Non-Small Cell Lung Carcinoma and Association with Clinicopathologic Features, Clin. Cancer Res. 16 (2010) 3743-3753. doi:10.1158/1078-0432.ccr-09-3352.

[44] Y. Mitsuishi, K. Taguchi, Y. Kawatani, T. Shibata, T. Nukiwa, H. Aburatani, M. Yamamoto, H. Motohashi, Nrf2 Redirects Glucose and Glutamine into Anabolic Pathways in Metabolic Reprogramming, Cancer Cell. 22 (2012) 66-79. doi:10.1016/j.ccr.2012.05.016.

[45] V.I. Sayin, S.E. LeBoeuf, S.X. Singh, S.M. Davidson, D. Biancur, B.S. Guzelhan, S.W. Alvarez, W.L. Wu, T.R. Karakousi, A.M. Zavitsanou, J. Ubriaco, A. Muir, D. Karagiannis, P.J. Morris, C.J. Thomas, R. Possemato, M.G.V. Heiden, T. Papagiannakopoulos, Activation of the NRF2 antioxidant program generates an imbalance in central carbon metabolism in cancer., ELife. 6 (2017). doi:10.7554/eLife.28083.

[46] J.L. Clarke, J.B. Murray, B.K. Park, I.M. Copple, Roles of Nrf2 in drug and chemical toxicity, Curr. Opin. Toxicol. 1 (2016) 104-110. doi:10.1016/j.cotox.2016.10.004.

[47] J. Adam, E. Hatipoglu, L. O'Flaherty, N. Ternette, N. Sahgal, H. Lockstone, D. Baban, E. Nye, G.W. Stamp, K. Wolhuter, M. Stevens, R. Fischer, P. Carmeliet, P.H. Maxwell, C.W. Pugh, N. Frizzell, T. Soga, B.M. Kessler, M. El-Bahrawy, P.J. Ratcliffe, P.J.C. Pollard, Renal cyst formation in Fh1deficient mice is independent of the Hif/Phd pathway: roles for fumarate in KEAP1 succination and Nrf2 signaling, Cancer Cell. 20 (2011) 524-537. doi:10.1016/j.ccr.2011.09.006.

[48] R. Nault, K.A. Fader, M.P. Kirby, S. Ahmed, J. Matthews, A.D. Jones, S.Y. Lunt, T.R. Zacharewski, Pyruvate Kinase Isoform Switching and Hepatic Metabolic Reprogramming by the Environmental Contaminant 2,3,7,8-Tetrachlorodibenzo-p-Dioxin, Toxicol. Sci. Off. J. Soc. Toxicol. 149 (2016) 358-371. doi:10.1093/toxsci/kfv245.

[49] M. Komatsu, H. Kurokawa, S. Waguri, K. Taguchi, A. Kobayashi, Y. Ichimura, Y.-S.S. Sou, I. Ueno, A. Sakamoto, K.I. Tong, M. Kim, Y. Nishito, S. lemura, T. Natsume, T. Ueno, E. Kominami, H. Motohashi, K. Tanaka, M. Yamamoto, The selective autophagy substrate p62 activates the stress responsive transcription factor Nrf2 through inactivation of Keap1, Nat. Cell Biol. 12 (2010) 213-223. doi:10.1038/ncb2021.

[50] A. Lau, Y. Zheng, S. Tao, H. Wang, S.A. Whitman, E. White, D.D. Zhang, Arsenic Inhibits Autophagic Flux, Activating the Nrf2-Keap1 Pathway in a p62-Dependent Manner, Mol. Cell. Biol. 33 (2013) 2436-2446. doi:10.1128/mcb.01748-12.

[51] A. Morandi, M.L. Taddei, P. Chiarugi, E. Giannoni, Targeting the Metabolic Reprogramming That Controls Epithelial-to-Mesenchymal Transition in Aggressive Tumors, Front. Oncol. 7 (2017) 40. doi:10.3389/fonc.2017.00040. 
[52] Z. Gao, Y. Bu, X. Liu, X. Wang, G. Zhang, E. Wang, S. Ding, Y. Liu, R. Shi, Q. Li, J. Fu, Z. Yu, TCDD promoted EMT of hFPECs via AhR, which involved the activation of EGFR/ERK signaling, Toxicol. Appl. Pharmacol. 298 (2016) 48-55. doi:10.1016/j.taap.2016.03.005.

[53] L.-C. Bui, C. Tomkiewicz, A. Chevallier, S. Pierre, A.-S. Bats, S. Mota, J. Raingeaud, J. Pierre, M. Diry, C. Transy, M. Garlatti, R. Barouki, X. Coumoul, Nedd9/Hef1/Cas-L mediates the effects of environmental pollutants on cell migration and plasticity, Oncogene. 28 (2009) 3642-3651. doi:10.1038/onc.2009.224.

[54] S. Pierre, A.-S. Bats, A. Chevallier, L.-C. Bui, A. Ambolet-Camoit, M. Garlatti, M. Aggerbeck, R. Barouki, X. Coumoul, Induction of the Ras activator Son of Sevenless 1 by environmental pollutants mediates their effects on cellular proliferation, Biochem. Pharmacol. 81 (2011) 304313. doi:10.1016/j.bcp.2010.10.003.

[55] C. Tomkiewicz, L. Herry, L.-C. Bui, C. Métayer, M. Bourdeloux, R. Barouki, X. Coumoul, The aryl hydrocarbon receptor regulates focal adhesion sites through a non-genomic FAK/Src pathway, Oncogene. 32 (2013) 1811-1820. doi:10.1038/onc.2012.197. 